\title{
Analysis of horizontal well productivity in tight gas formations and its sensitivity to reservoir properties
}

\author{
Rasa Soleimani ${ }^{1} \cdot$ Yaser Jahanpeyma ${ }^{2} \cdot$ Mohammad Salehian $^{3}$ (D)
}

Received: 16 May 2018 / Accepted: 31 August 2018 / Published online: 7 September 2018

(c) The Author(s) 2018

\begin{abstract}
Horizontal wells are frequently used in gas reservoirs to enhance the production performance by increasing the contact surface of the well with the formation. Although some methods have been presented to evaluate vertical well productivity in tight gas reservoirs, the detailed information regarding horizontal wells has not yet been deeply addressed. This study uses a modified backpressure test method based on the isochronal test to determine the correct value of the productivity of horizontal wells in a pressure-dependent viscosity anisotropic tight gas formation. To use the isochronal test calculations in the modified backpressure test, the "process conversion-flowing pressure correction" approach was used to convert the modified backpressure test process into the isochronal test. The comparison between productivity values before and after correction with the simulation results validates that how this method can successfully estimate the productivity in horizontal wells. We perform a sensitivity analysis on the error between the pseudo-pressure before and after correction and show its variation with porosity, permeability, skin, formation thickness, and temperature. This can be helpful to understand the importance of correcting pseudo-pressure under different conditions. Results validate that the proposed method of productivity analysis is needed for horizontal wells and should be applied especially in low permeable and thin (tight gas) formations to acquire the precise value of productivity.
\end{abstract}

Keywords Well productivity $\cdot$ Horizontal well testing $\cdot$ Tight gas formation $\cdot$ Modified isochronal test $\cdot$ Back-pressure test

\section{List of symbols}

$C_{\mathrm{t}} \quad$ Total formation compressibility factor, $\mathrm{Psi}^{-1}$

$D \quad$ Non-Darcy flow coefficient, (MMSCF.D $\left.{ }^{-1}\right)^{-1}$

$k_{\mathrm{H}} \quad$ Reservoir horizontal permeability, md

$k_{\mathrm{V}} \quad$ Reservoir vertical permeability, md

$L \quad$ Horizontal well length; $\mathrm{ft}$

$P_{\text {wf }} \quad$ Bottom hole flowing pressure, psi

$q_{\mathrm{sc}}$ Gas wellhead production under standard conditions, MMSCF. ${ }^{-1}$

$r_{\mathrm{w}} \quad$ Wellbore radius, $\mathrm{ft}$

$S \quad$ Mechanical skin factor, dimensionless

$S_{\mathrm{a}} \quad$ Apparent skin factor, dimensionless

$S_{z} \quad$ Skin factor due to partial penetration, dimensionless

Mohammad Salehian

mohammadsalehiyan@gmail.com

1 Department of Chemical and Petroleum Engineering, University of Calgary, Calgary, Canada

2 Dana Energy Company, Tehran, Iran

3 Department of Petroleum and Natural Gas Engineering, Istanbul Technical University, Istanbul, Turkey

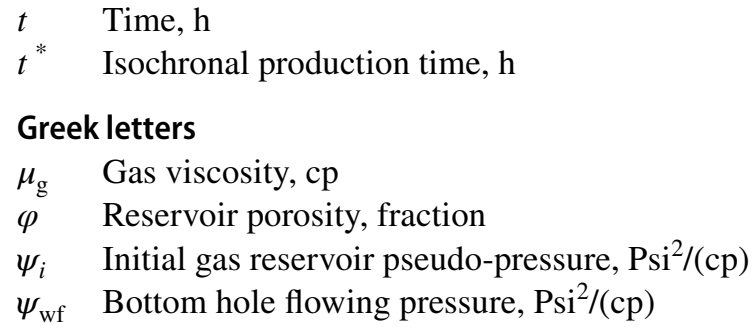

\section{Subscripts}

$k, j \quad$ The $k$ th and $j$ th working system

$\mathrm{t}$ Test

iso Isochronal

\section{Introduction}

Horizontal wells are applicable in low- as well as high-permeability gas reservoirs (Joshi 1991; Weihong et al. 2005). In low-permeability fields, horizontal wells drain larger volumes than vertical wells and provide an alternative way to achieve long penetration lengths to the formation. In addition, they reduce near-wellbore turbulence and enhance well deliverability in high-permeability gas formations 
(Chaudhry 2003). Nevertheless, well testing analysis in horizontal gas wells is more difficult compared to the vertical gas wells due to the complexity of mathematical models and assumptions (Joshi 1991).

Several efforts have been made to determine the productivity of gas wells. Brekke and Thompson (1996) developed an upscaling network simulator for comprehensive flow prediction of horizontal wells producing single-phase fluids. They predicted well productivity within an accuracy of $1 \%$ when compared to fine grid reservoir simulations. Dietrich and Kuo (1996) employed an explicit modeling procedure including high-resolution grid systems and eliminated the use of a well model to indicate that using typical field-scale grid systems yields overestimated the well productivity by as much as $50 \%$, which is due to the Peaceman horizontal well model and grid effects. Raghavan and Ambastha (1998) introduced a mathematical model to estimate the productivity of multilateral completions. They also used the proposed model to investigate the impacts of reservoir properties and boundaries on multilateral well productivity. Basquet et al. (1999) considered the effect of cross-flow in multilayered reservoirs and proposed a semi-analytical approach to predict the productivity of complex wells. An experimental and theoretical investigation of multilateral/dual lateral horizontal well productivity in areally anisotropic reservoirs was presented by Yildiz (2005). These studies, however, did not provide an applicable incorporation of well testing and productivity estimation method for unconventional reservoirs. Clarkson et al. (2012) extended the dynamicslippage concept to shale gas formations. They developed a numerical model that accounts for multi-mechanism flow and modified the modern rate-transient analysis methods to include the dynamic slippage and desorption effects. Clarkson (2013) then reviewed analytical, numerical and empirical methods of production analysis in unconventional gas reservoirs. He also provided field examples and discussed the future development of production data analysis techniques. Wattenbarger et al. (1998) and Xu et al. (2013) analyzed the production performance of naturally fractured tight gas wells. Although these papers provided detailed insight into either productivity evaluation techniques or production analysis in shale gas formations, a fast, simple and accurate productivity prediction approach is still required for horizontal wells in tight gas formations. This work focuses on the utilization of a backpressure test to evaluate horizontal gas well productivity in tight gas reservoirs via a straightforward superpositionbased method.

The backpressure test is widely used to evaluate the productivity of individual gas wells (Al-Hussainy and Ramey Jr 1966; Fetkovich 1973). However, the long time for pressure stabilization and the vent of gas in low-permeability gas reservoirs makes this test inapplicable (Hui et al. 2014). Hui et al. (2014) proposed a modified backpressure test based on the idea of isochronal test to overcome the mentioned problems. On the other hand, the productivity calculation methods of isochronal test cannot be used in modified back pressure test data because it would result in overestimating the pressure drawdown, and therefore, underestimating the productivity. To address this issue, Hui et al. (2014) proposed the "process conversion-flowing pressure correction" method in which the bottom hole flowing pressure of the modified back pressure test should be transformed into the equivalent pressure of the isochronal test.

The traditional back pressure test consists of three or four continuous incremental production working systems, measuring the gas flow rate and the bottom hole flowing pressure at the stable values and then, shutting the well to recover the pressure to the average reservoir pressure (Hui et al. 2014). This approach is shown in Fig. 1a. As the gas rate and the bottom hole flowing pressure values are stabilized, this method can provide the value of productivity accurately. Having a low-permeability gas reservoir, given that the gas flow rate increases in each working system, it requires a long time for stabilization and vents a large amount of gases, which is detrimental for the environment. Thus, this approach cannot be a good choice for low-permeability gas reservoirs.

Cullender (1955) presented the isochronal test method that is schematically shown in Fig. 1b. It includes intermittent production and build-up for 3-4 working systems with the increasing rate at equal time intervals. Afterward, performing a long-time production continues until both the gas rate and the bottom
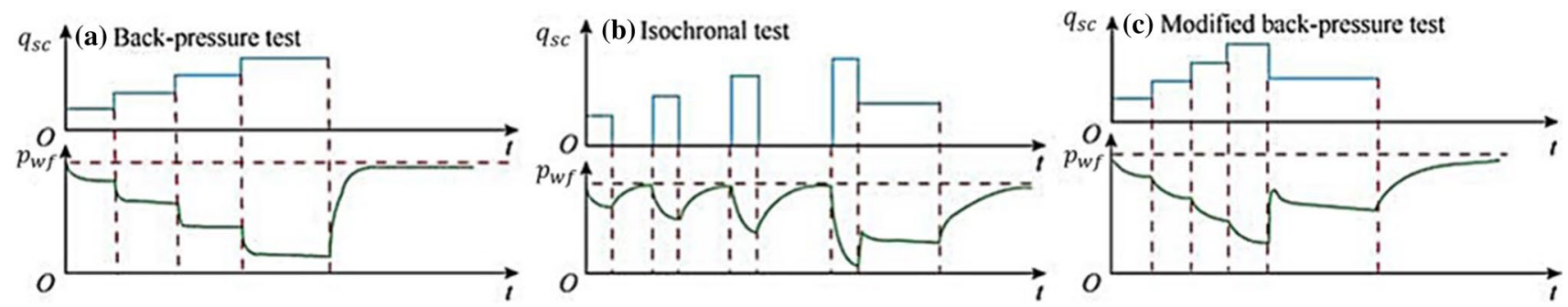

Fig. 1 Schematic representation of the backpressure test, isochronal test, and modified backpressure test (after Hui et al. 2014) 
hole flowing pressure reach the stability. Finally, the well will be shut to recover the pressure to the initial formation pressure. Using this approach, the flowing pressure does not need to reach the stabilization, but the frequent shut-in (build-up) periods among production intervals to recover the pressure to the initial reservoir pressure is the main disadvantage of this method. Moreover, the isochronal method is more complex than the backpressure method and requires a longer time to perform. hole flowing pressure in modified backpressure must be corrected to the equivalent pressure in an isochronal test, assuming that all circumstances are identical in both tests. By doing so, the isochronal test calculation method is usable in modified backpressure test data. For a homogeneous infinite acting gas reservoir, the drawdown pseudo-pressure equation for a horizontal gas well in unsteady flow conditions is as follows (Chaudhry 2003):

$\left(\Psi_{i}-\Psi_{\mathrm{wf}}\right)_{t_{i}}=\frac{57.920 \times 10^{-3} T_{\mathrm{f}} P_{\mathrm{sc}}}{k h T_{\mathrm{sc}}} q_{i}\left[\sum_{j=1}^{i} \frac{q_{j}-q_{j-1}}{q_{i}} \log \left(t_{i}-t_{j-1}\right)+\log \left(\frac{k}{\Phi \mu_{g_{i}} c_{i} r_{\mathrm{w}}^{2}}\right)-3.23+0.869 S \prime\right]$

The need for multiple shut-in periods and the long time for stabilization in mentioned methods, which introduces economical environmental problems, was solved by Hui et al. (2014) after developing the modified backpressure test. In this method, well produces at identical working systems, the bottom-hole flowing pressure is not needed to reach stability and there is no need to shut-in the well. Before the final shut-in that allows pressure recovering back to the initial formation pressure, a prolonged production period was to make both production and flowing pressure reach stability so that the obtained productivity would demonstrate formation characteristics accurately. This process is shown in Fig. 1c. Other authors also provided studies on gas well testing methods and fluid flow through porous media (Daiyong et al. 2006; Liang et al. 2013; Xiaoping and Yun 2004).

If the equations of isochronal test productivity calculation were directly used for modified backpressure test data, the obtained productivity would be erroneous since there are no shut-in periods in the modified backpressure test and thus the pressure drop in each step will be affected by the previous one. Hence, the modified backpressure test method requires a new productivity calculation procedure. This study applied the "process conversion-flowing pressure correction" approach, first utilized by Hui et al. (2014) for vertical wells, into horizontal wells in anisotropic lowpermeability gas reservoirs and presents the correct way of determining the productivity of a horizontal well if the viscosity is a pressure-dependent parameter.

\section{Mathematical model}

Hui et al. (2014) assumed a shut-in pressure build-up process between every two unsteady working systems of modified backpressure test to allow the pressure recover up to the initial formation pressure. Therefore, the converted bottom where

$S^{\prime}=S+D q$

here $S$ is the rate-dependent skin factor and $D$ represents the non-Darcy flow coefficient [(MMSCF.D $\left.{ }^{-1}\right)^{-1}$ ]. The variables in Eq. (1) and the remaining equations of this study are in oilfield units. According to the literature, formation pressure affects the viscosity of the gas. Thus, to obtain realistic results, the gas viscosity should be considered as a parameter that is dependent on pressure. To accomplish this, the empirical formula proposed by Danesh (1998) was utilized to determine the gas viscosity. The non-Darcy flow coefficient $D$ in Eq. (2) is another pressure-dependent variable. We use the Chaudhry (2003) relationship to account for the effect of pressure on $D$ coefficient. The correlations of gas viscosity and non-Darcy flow coefficient are explained in "Appendix".

If all circumstances are identical in both tests, the isochronal test flowing pseudo-pressure correction term can be obtained from Eq. (3):

$$
\begin{aligned}
\Delta \Psi_{i}= & \frac{57.920 \times 10^{-3} T_{\mathrm{f}} P_{\mathrm{sc}}}{k h T_{\mathrm{sc}}} \\
& q_{i}\left[\sum_{j=1}^{i} \frac{q_{j}-q_{j-1}}{q_{i}} \log \left(t_{i}-t_{j-1}\right)-\log \left(t_{j}-t_{j-1}\right)\right]
\end{aligned}
$$

Therefore, the conversion of pseudo-pressure from modified backpressure to the similar isochronal test can be performed by the following expression:

$\left(\Psi_{i}-\Psi_{\text {wf }}\right)_{\text {iso }_{i}}=\left(\Psi_{i}-\Psi_{\text {wf }}\right)_{t_{i}}-\Delta \Psi_{i}$

Equation. (4) represents the converted isochronal test drawdown pseudo-pressure at the $j$ th working system from the identical modified backpressure test data. Hui et al. (2014), without considering the effect of pressure on viscosity and non-Darcy coefficient, validated the previous equations for the vertical gas wells. In horizontal wells, however, an equivalent well radius should be calculated to account for an anisotropic system. 


$$
r_{\mathrm{w}}=\frac{r_{\mathrm{eh}} \frac{L}{2}}{a\left[1+\sqrt{1-\left(\frac{L}{2 a}\right)^{2}}\right]\left[\frac{\beta h}{2 r_{\mathrm{w}}}\right]^{\frac{h}{L}}}
$$

where:

$r_{\mathrm{eh}}=\left[\left(\frac{L}{2}+r_{\mathrm{ev}}\right) r_{\mathrm{ev}}\right]^{0.5}$

The parameters $a$ and $\beta$ can be calculated using the following expressions (Joshi 1991):

$a=0.5 L\left[0.5+\left(0.25+\left(\frac{2 r_{\mathrm{eh}}}{L}\right)^{4}\right)^{0.5}\right]^{0.5}$

\section{Validation of the method}

In this section, a modified backpressure test was performed to estimate the productivity of the horizontal gas well. We

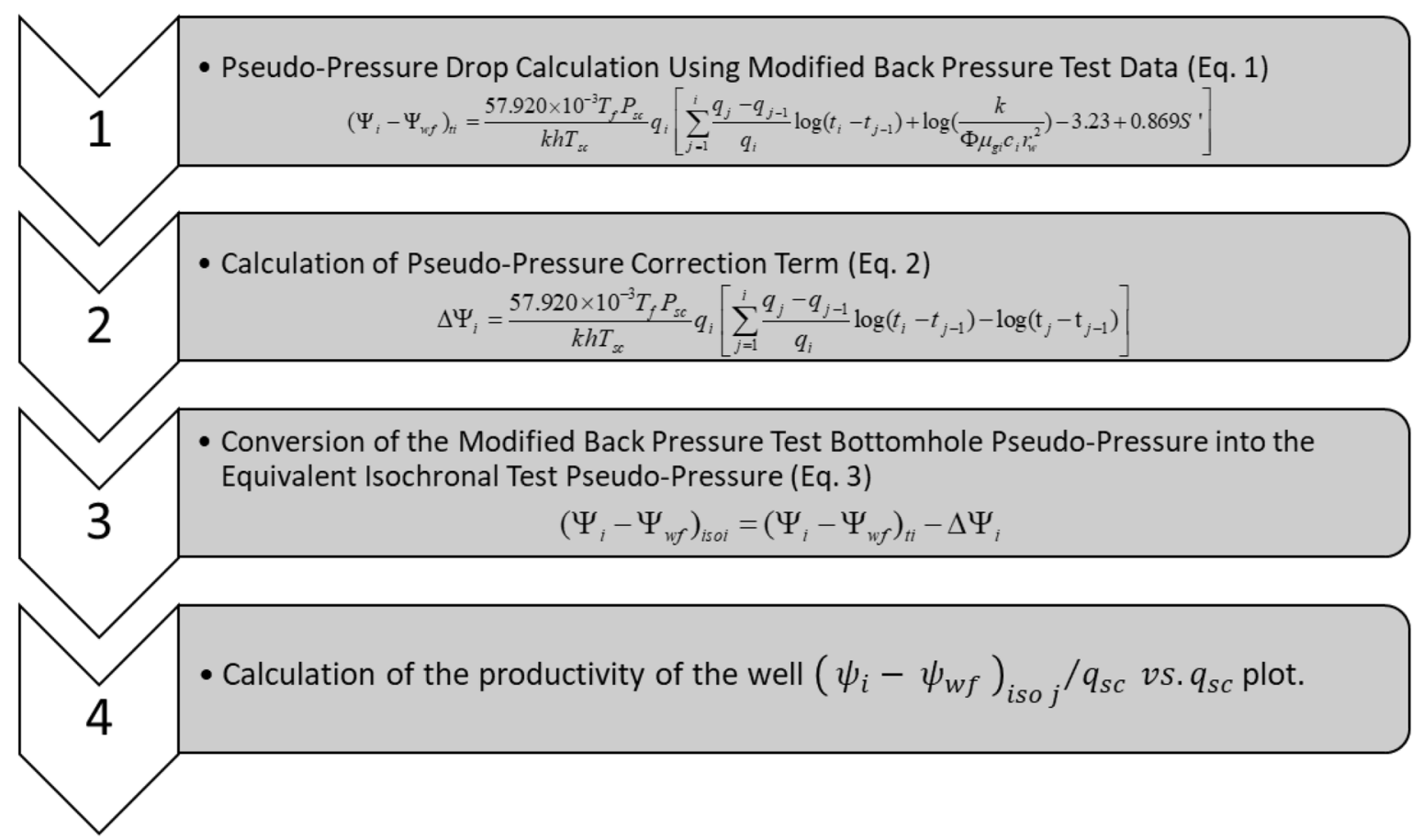

Fig. 2 Schematic view of productivity calculation process for any working system

Fig. 3 Schematic description of horizontal well \#1 in a synthetic reservoir

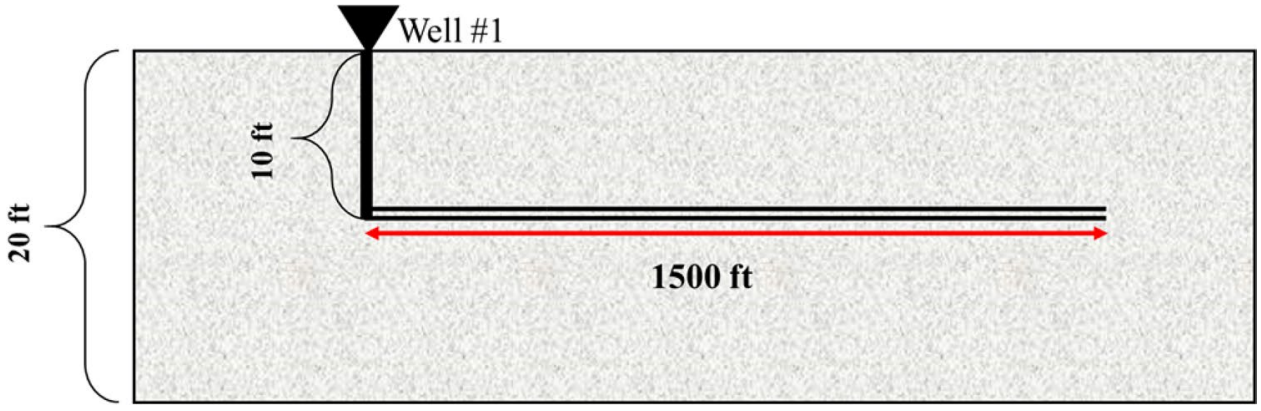




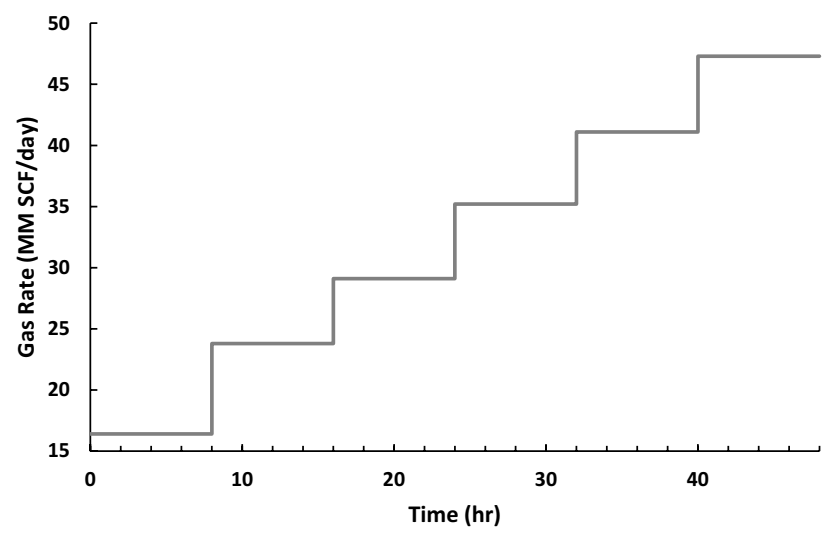

Fig. 4 Gas rate production vs. time in modified backpressure test at well \#1

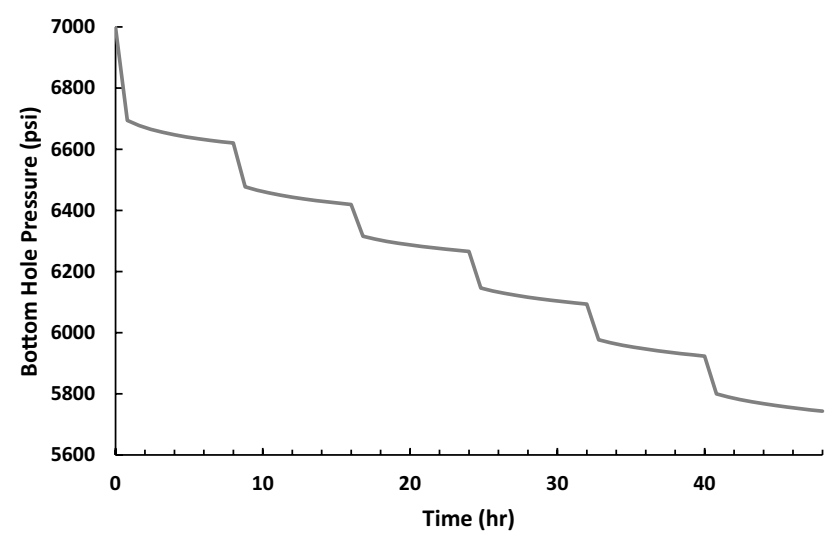

Fig. 5 Bottom hole pressure vs. time in modified backpressure test at well \#1

consider a synthetic example that is created by commercial black oil simulator Eclipse 100 and perform six production periods as a working system, where each period lasts $8 \mathrm{~h}$. Figure 3 depicts the configuration of the horizontal "well \#1" in the synthetic reservoir. As we aim to evaluate the productivity in unstable working systems, we eliminate the prolonged production period in the synthetic example, which was explained as the last working system of modified backpressure test. Figures 4 and 5 show the gas rate and bottomhole pressure of the test.

Table 1 shows the time of the test, flow rates, bottom hole pressure values of "well \#1" associated with the productivity before (explicit use of isochronal test calculations for modified backpressure test) and after correction (equivalent isochronal test). The reservoir and fluid properties used in the simulation and calculation procedure are presented in Table 2 . The uncertain models could be utilized as multiple realizations for developing upscaling network (Brekke and Thompson 1996) or field development purposes (Sefat et al. 2016). However, this study aims to develop a mathematical method for productivity calculation. Thus, similar to several previous works in the literature (Hui et al. 2013), since no real-field data is available in this study, the commercial black oil simulator (Eclipse 100) has been used as a reference and no uncertainty is associated with the input parameters. The idea is to perform a modified backpressure test in the synthetic field and validate the productivity values obtained by "process conversion-flowing pressure correction" approach by comparing them to those generated by the commercial simulator.

Figure 6 shows the pseudo-pressure difference per rate (the pseudo-pressure is usually reported per rate to obtain a linear behavior and interpret easily) versus rate obtained by three different methods; direct use of isochronal test (before correction), conversion to the equivalent isochronal test (after correction), numerical simulation results. The results show that the corrected data are in perfect agreement with the data calculated by the numerical model, which validates that the proposed method can successfully deliver the accurate productivity of a horizontal gas well.

\section{Error analysis}

As characteristics of the formation affect the difference between pseudo-pressure before and after correction, analysis of this difference would provide useful information about how "process conversion-flowing pressure correction" approach acts in horizontal gas wells. An error parameter is defined as the sum of square error between pseudo-pressure before $\left(t_{i}\right)$ and after $\left(\right.$ iso $\left._{i}\right)$ the correction. Large error value would show the negligible difference between the two items, which means
Table 1 Productivity test data of well \#1

\begin{tabular}{|c|c|c|c|c|c|}
\hline Test no. & $\begin{array}{l}\text { Test time } \\
\text { (h) }\end{array}$ & $q_{\mathrm{sc}}\left(\mathrm{MMSCF} \mathrm{D}^{-1}\right)$ & $P_{\mathrm{wf}}(\mathrm{psi})$ & $\begin{array}{l}\left(\psi_{i}-\psi_{\mathrm{wf}}\right)_{t j} / q_{\mathrm{sc}} \\
\left(\mathrm{MMpsi}^{2} \text { day }\right. \\
\left(\mathrm{cp} . \mathrm{MMSCF}^{-1}\right)\end{array}$ & $\begin{array}{l}\left(\psi_{i}-\psi_{\mathrm{wf}}\right)_{\text {iso } j} / q_{\mathrm{sc}} \\
\left(\mathrm{MMpsi}^{2} \text { day }\right. \\
\left(\mathrm{cp} \cdot \mathrm{MMSCF}^{-1}\right)\end{array}$ \\
\hline 1 & 8 & 16.41 & 7039.34 & 6.44 & 6.44 \\
\hline 2 & 8 & 23.79 & 6136.19 & 9.75 & 9.11 \\
\hline 3 & 8 & 29.13 & 5340.54 & 11.88 & 11.01 \\
\hline 4 & 8 & 35.21 & 4482.06 & 14.34 & 13.23 \\
\hline 5 & 8 & 41.07 & 3609.94 & 16.71 & 15.34 \\
\hline 6 & 8 & 47.30 & 2684.96 & 19.20 & 17.58 \\
\hline
\end{tabular}


Table 2 The constant parameters

\begin{tabular}{ll}
\hline Constants & Values \\
\hline Formation temperature, $T_{\mathrm{f}}$ & $240{ }^{\circ} \mathrm{F}$ \\
Porosity, $\varphi$ & $7 \%$ \\
Gas viscosity, $\mu$ & Variable value \\
Vertical permeability, $k_{\mathrm{v}}$ & $0.1 \mathrm{md}$ \\
Horizontal permeability, $k_{\mathrm{h}}$ & $0.25 \mathrm{md}$ \\
Well length, $L$ & $1500 \mathrm{ft}$ \\
Wellbore radius, $r_{\mathrm{w}}$ & $0.5 \mathrm{ft}$ \\
Formation thickness, $h$ & $20 \mathrm{ft}$ \\
Depth of the top of formation, $Z$ & $7000 \mathrm{ft}$ \\
Total compressibility, $C_{\mathrm{t}}$ & $6 \times 10^{-5} \mathrm{psi}^{-1}$ \\
Skin factor & 2.5 \\
\hline
\end{tabular}

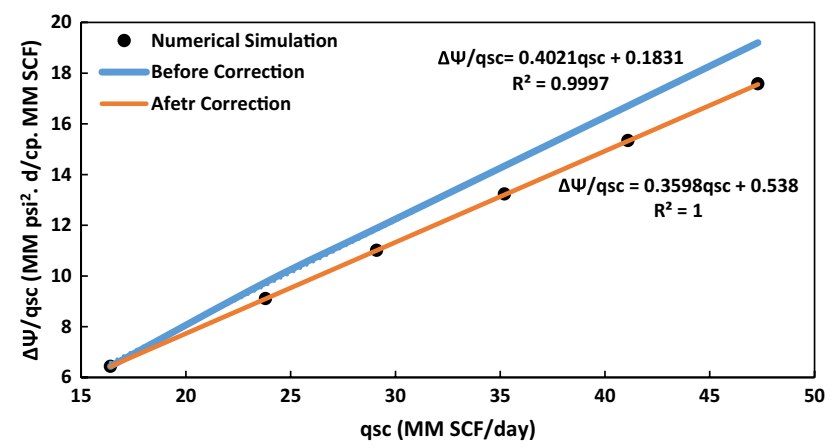

Fig. 6 Productivity analysis of horizontal well \#1 using pseudo-pressure rate per rate vs. rate

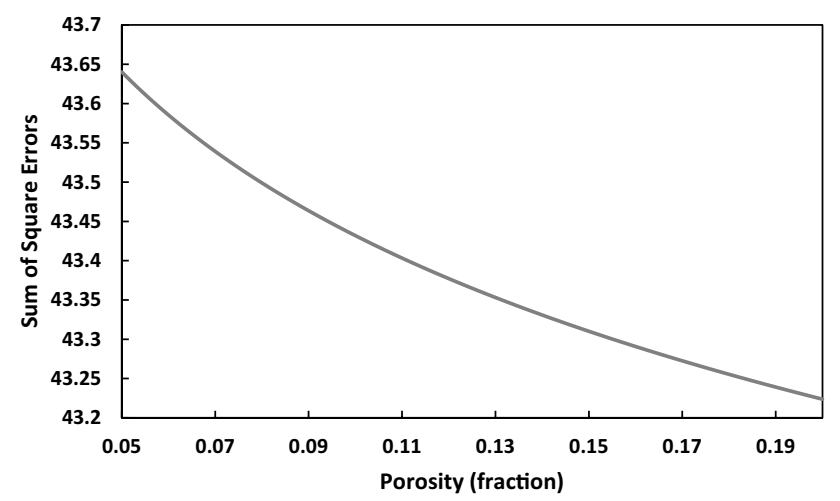

Fig. 7 The impact of porosity on the error between pseudo-pressure before and after correction

that the explicit use of isochronal test calculations in modified backpressure test would result in erroneous productivity values. This error can be calculated using the following equation.

Error $=\sqrt{\sum_{i=1}^{n}\left[\left(\Psi_{i}-\Psi_{\mathrm{wf}}\right)_{\mathrm{iso}_{i}}-\left(\Psi_{i}-\Psi_{\mathrm{wf}}\right)_{t_{i}}\right]^{2}}$

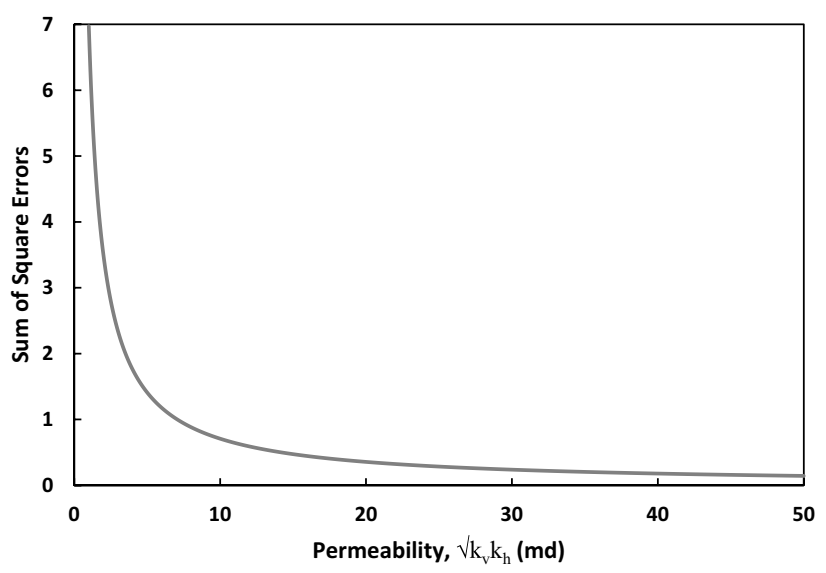

Fig. 8 The impact of permeability $\left(\sqrt{ } k_{\mathrm{v}} k_{\mathrm{h}}\right)$ on the error between pseudo-pressure before and after correction

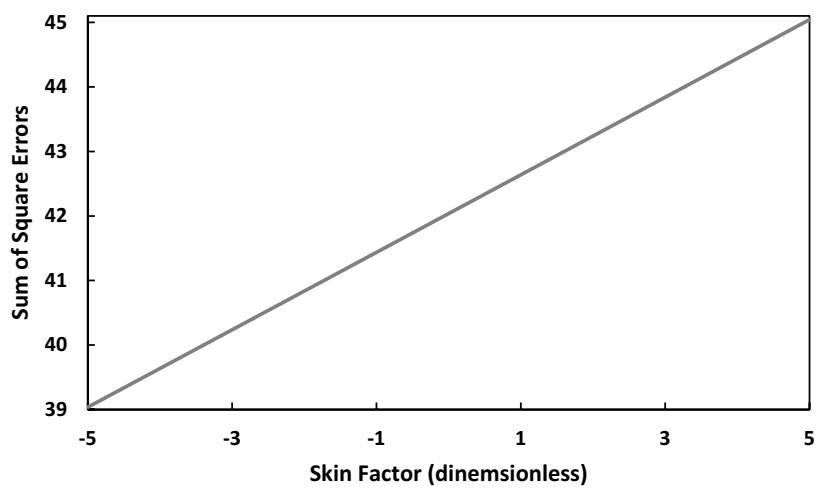

Fig. 9 The impact of skin factor on the error between pseudo-pressure before and after correction

We perform an analysis on the sensitivity of the error to the porosity, permeability $\left(\sqrt{ } k_{\mathrm{v}} k_{\mathrm{h}}\right)$, skin factor, formation thickness, and reservoir temperature. As the first case, Fig. 7 exhibits the effect of porosity of a homogeneous reservoir on the error parameter. The results show that the porosity does not affect the error value remarkably. However, the modified approach is more accurate in the reservoirs with lower porosity, as the corrected pseudo-pressure (iso ${ }_{i}$ ) approaches the isochronal-based pseudo-pressure $\left(t_{i}\right)$ in higher porosity formations.

Figure 8 demonstrates that unlike the porosity, permeability has a noticeable effect on the pseudo-pressure error. It can be seen that in the low-permeability cases, the error extremely increases. This indicates that using the proposed method in this study is vital in lower permeability formations to avoid wrong productivity analysis.

Figure 9 depicts the sensitivity of pseudo-pressure error to the skin factor, showing that the error value increases when the skin value is higher. Although the effect of skin 


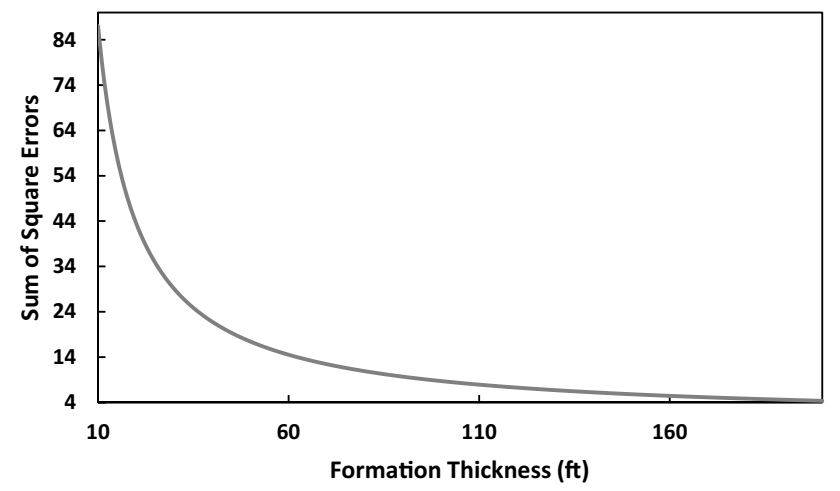

Fig. 10 The impact of formation thickness on the error between pseudo-pressure before and after correction

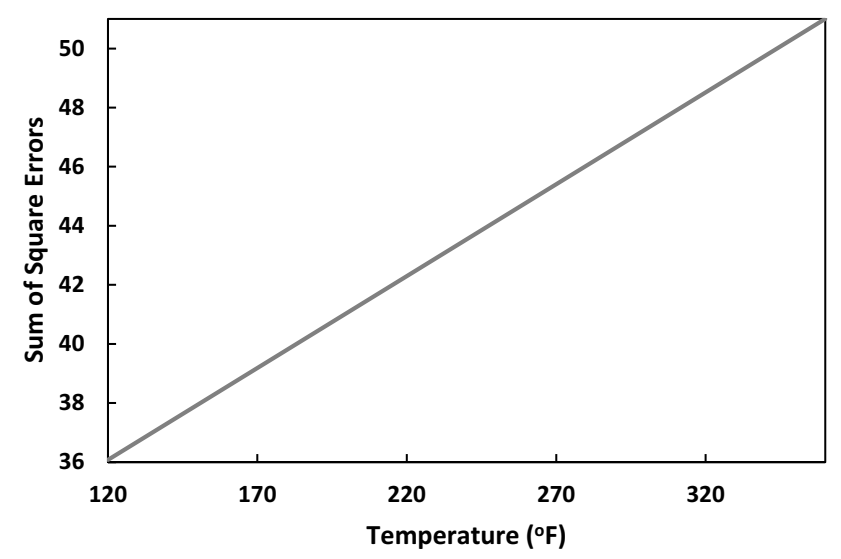

Fig. 11 The impact of formation temperature on the error between pseudo-pressure before and after correction

is lower than the permeability effect, it can be seen that in highly damaged formations, the "process conversion-flowing pressure correction" method is more important to obtain accurate productivity values.

Figure 10 exhibits the relationship between reservoir thickness and the pseudo-pressure error. The error shows similar behavior to the permeability, as it exponentially increases in the case of thin reservoirs. In addition, in formations with more thickness, there is even no need to drill a horizontal well, as it is known that horizontal wells are usually used in thin reservoirs. Thus, in thick reservoirs, where the radius of investigation of the horizontal well cannot cover the whole reservoir flow (drainage error), using the modified method becomes more needed to prevent false productivity values.

Figure 11 displays the variation of pseudo-pressure error with different values of temperature. Based on the results, it is evident that the error linearly increases with the reservoir temperature increasing and thus it is necessary to use the new method to acquire the true productivity of horizontal gas well in higher temperature values. In fact, all variables that are linearly dependent on pseudopressure in Eq. (1) are in a relationship with the error parameter as well.

\section{Conclusion}

This study applies a new approach for determining the accurate productivity of horizontal wells in tight gas formations. We use the modified backpressure test based on the idea of isochronal test and utilize the "process conversion-flowing pressure correction" method in horizontal gas wells to overcome the erroneous productivity values delivered by the direct use of isochronal test calculations. We validate this method for horizontal gas wells by applying it to the synthetic example and comparing the productivity obtained from numerical simulation with the productivity calculated by converting the process of modified backpressure test into the isochronal test.

We also performed an error analysis to investigate the difference between pseudo-pressure before and after correction to examine the importance of the proposed method in different conditions. It was shown that the error between true and false pseudo-pressure increases in lower porosity, more severe damage (higher skin), and/or higher temperature reservoirs. Results indicated that it is vital to correct the pseudo-pressure in low-permeability thin (tight) gas formations, as explicit use of isochronal test calculations results in highly erroneous pseudo-pressure and thus productivity in these conditions.

\section{Appendix}

\section{Empirical correlation for gas viscosity by Danesh (1998)}

$\mu_{\mathrm{g}}=10^{-4} \cdot a \cdot \exp \left(b\left(\frac{\rho}{62.43}\right)^{c}\right)$

where

$a=(9.379+0.01009 M) T^{1.5} /(2019.2+19.26 M+T)$

$b=3.448+0.1009 M+(986.4 / T)$

$c=2.4-0.2 b$ 


\section{Correlation for non-Darcy flow coefficient by Chaudhry (2003)}

$D=\frac{0.0518 \gamma_{\mathrm{g}}}{\mu_{\mathrm{g}} h r_{\mathrm{w}} k^{0.2}}$

The molecular weight $M$ and specific gravity are assumed 16.043 and 0.553 , respectively.

Open Access This article is distributed under the terms of the Creative Commons Attribution 4.0 International License (http://creativeco mmons.org/licenses/by/4.0/), which permits unrestricted use, distribution, and reproduction in any medium, provided you give appropriate credit to the original author(s) and the source, provide a link to the Creative Commons license, and indicate if changes were made.

\section{References}

Al-Hussainy R, Ramey H Jr (1966) Application of real gas flow theory to well testing and deliverability forecasting. J Petrol Technol 18:637-642

Basquet R, Caltagirone J, Alabert F, Batsalle J (1999) A semianalytical approach for productivity evaluation of complex wells in multilayered reservoirs. SPE Reserv Eval Eng 2:506-513

Brekke K, Thompson LG (1996) Horizontal well productivity and risk assessment. In: SPE annual technical conference and exhibition. Society of Petroleum Engineers, Dallas

Chaudhry A (2003) Gas well testing handbook. Gulf Professional Publishing, Houston

Clarkson CR (2013) Production data analysis of unconventional gas wells: review of theory and best practices. Int J Coal Geol 109:101-146

Clarkson CR, Nobakht M, Kaviani D, Ertekin T (2012) Production analysis of tight-gas and shale-gas reservoirs using the dynamicslippage concept. SPE J 17:230-242

Cullender M (1955) The isochronal performance method of determining the flow characteristics of gas wells. Society of Petroleum Engineers, Richardson
Daiyong L, Fangxia B, Ping L (2006) Deliverability analytical approach of gas well. Nat Gas Ind 26:100

Danesh A (1998) PVT and phase behaviour of petroleum reservoir fluids, vol 47. Elsevier, London

Dietrich J, Kuo S (1996) Predicting horizontal well productivity. J Can Petrol Technol 35:60-62

Fetkovich M (1973) The isochronal testing of oil wells. In: Fall meeting of the Society of Petroleum Engineers of AIME. Society of Petroleum Engineers, Dallas

Hui L, Rui G, Junchang D, Li L, Yang L, Yingjie Y (2013) Productivity evaluation and influential factor analysis for Sarvak reservoir in South Azadegan oil field. Iran Petrol Explor Dev 40:627-634

Hui W et al (2014) Evaluation of gas well productivity in low permeability gas reservoirs based on a modified back-pressure test method petroleum. Explor Dev 41:500-503

Joshi SD (1991) Horizontal well technology. PennWell Books

Liang T, Chang Y, Xiaofei G, Baolei L, Jian W (2013) Influence factors of single well's productivity in the Bakken tight oil reservoir. Williston Basin Petrol Explor Dev 40:383-388

Raghavan R, Ambastha A (1998) An assessment of the productivity of multilateral completions. J Can Petrol Technol 37:58-67

Sefat MH, Elsheikh AH, Muradov KM, Davies DR (2016) Reservoir uncertainty tolerant proactive control of intelligent wells Comput Geosci 20:655-676

Wattenbarger RA, El-Banbi AH, Villegas ME, Maggard JB (1998) Production analysis of linear flow into fractured tight gas wells. In: SPE rocky mountain regional/low-permeability reservoirs symposium. Society of Petroleum Engineers, Dallas

Weihong W, Pingping S, Xinhua M, Ailin J (2005) Data analysis method of gas well productivity test for low permeable gas reservoirs. Nat Gas Ind 25:76

Xiaoping L, Yun L (2004) A new way to analyze productivity of gas wells. Nat Gas Ind 24:76-77

Xu B, Haghighi M, Li X, Cooke D (2013) Development of new type curves for production analysis in naturally fractured shale gas/tight gas reservoirs. J Petrol Sci Eng 105:107-115

Yildiz T (2005) Multilateral horizontal well productivity. In: SPE Europec/EAGE annual conference. Society of Petroleum Engineers, Dallas

Publisher's Note Springer Nature remains neutral with regard to jurisdictional claims in published maps and institutional affiliations. 